\title{
Nerve function impairment in leprosy: design, methodology, and intake status of a prospective cohort study of 2664 new leprosy cases in Bangladesh (The Bangladesh Acute Nerve Damage Study)
}

\author{
RICHARD P. CROFT*, JAN H. RICHARDUS**, \\ PETER G. NICHOLLS+ \& W. CAIRNS S. SMITH+ \\ *The Leprosy Mission, Danish Bangladesh Leprosy Mission, \\ Nilphamari, Bangladesh \\ **Departments of Public Health, Erasmus University Rotterdam, \\ The Netherlands \\ +Department of Public Health, University of Aberdeen, Scotland, UK
}

\author{
Accepted for publication 20 December 1998
}

\begin{abstract}
Summary The Bangladesh Acute Nerve Damage Study (BANDS) is a prospective cohort study designed to investigate epidemiological, diagnostic, therapeutic and operational aspects of acute nerve function impairment in leprosy. The study is based at a single centre in Bangladesh, in an area with a high prevalence of leprosy. The centre, Danish Bangladesh Leprosy Mission, has a well-established vertical leprosy control programme. In this paper, the study design and methodology are described, together with definitions of nerve function impairment (NFI) used in this and subsequent papers. The study recruited 2664 new leprosy cases in a 12-month period. The male:female ratio is $1 \cdot 25: 1$, and $17.61 \%$ of the cohort are under 15 years of age. In all, $83.33 \%$ of the cohort are paucibacillary (PB), and $16.67 \%$ multibacillary (MB). However, the MB rate amongst males is $19.72 \%$, and amongst females is $12.85 \%$, despite an equal period of delay to diagnosis. $55 \%$ of patients presented for treatment within 12 months of developing symptoms. $6 \cdot 12 \%$ of the total number of cases were smear positive, and $36.71 \%$ of the MB cases were smear positive. $9.61 \%$ of the total number of cases were graded as having World Health Organisation (WHO) disability grade 1 , and $5.97 \%$ had grade 2. Amongst MB cases, $27.48 \%$ had WHO grade 1 disability present, and $18.24 \%$ had grade 2 present, compared with $6.04 \%$ and $3.51 \%$, respectively, amongst PB cases. A total of $11.90 \%$ of the cohort had sensory NFI of any kind, and $7.39 \%$ had motor NFI. Ninety patients presented with NFI needing treatment (3.38\%), and of these, $61(67.78 \%)$ had silent NFI. MB patients had a prevalence of reaction/NFI needing treatment nearly 7 times higher than PB cases (15.32\% amongst MB; $2.30 \%$ amongst PB), and males nearly double that of females (5.67\% amongst males, $2.96 \%$ amongst females). The most
\end{abstract}


commonly affected nerve by function impairment was the posterior tibial (sensory) with $6.46 \%$ of nerves affected $(9.38 \%$ of patients), followed by the ulnar nerve with $3.23 \%$ of nerves impaired (5.56\% of patients). Future research and publications, building on this foundation, will focus on the following areas: the incidence of NFI and reactive events, the risk factors for developing NFI, and the response to treatment of patients developing acute NFI.

\section{Introduction}

Although leprosy is known primarily as a skin disease, it is nerve damage and the resulting disabilities that set the disease apart in people's minds. It is accepted that leprosy control programmes should include both the provision of chemotherapy as well as activities to actively prevent the occurrence of impairments. Understanding of the process and epidemiological patterns of nerve function impairment (NFI) in leprosy is essential for the development of methods to predict, detect and manage this problem.

There are still many difficulties and unsolved problems concerning nerve function impairment. ${ }^{1}$ In the first place, definitions and diagnosis of NFI in leprosy have not been consistent. Early detection is essential for the successful treatment of NFI and more understanding is needed of risk factors and the reasons for diagnostic delay. In addition, applicable methods for early detection under field conditions are limited and are often not properly validated.

Epidemiological investigations have usually been limited to certain causes of NFI (e.g. type I and type II reaction), and are often retrospective and hospital based, ${ }^{2-6}$ with some exceptions. ${ }^{7,8}$ Van Brakel $^{2}$ has drawn attention to the absence of any prospective studies designed to establish the incidence rates of the various leprosy reactions.

Since knowledge of NFI is so fragmented, a systematic research programme was initiated in a well-established leprosy control programme in a highly endemic area of Bangladesh. ${ }^{9}$ The programme is called the Bangladesh Acute Nerve Damage Study (BANDS), and its objective is to study the epidemiological, diagnostic, therapeutic and operational aspects of (acute) NFI in detail by means of a prospective cohort study of newly diagnosed leprosy patients. This paper explains the objectives, study design, research questions, definitions, and data procedures of BANDS, and describes the cohort of leprosy patients at the time of recruitment into the cohort.

\section{Definition and concept of NFI}

Although this study received the acronym BANDS, with 'ND' standing for nerve damage, the more correct nomenclature is nerve function impairment, or NFI. This follows the International Classification of Impairments, Disabilities and Handicap (ICIDH) as recommended by the WHO. ${ }^{10}$ In ICIDH 'impairment' is defined as 'any loss or abnormality of psychological, physiological, or anatomical structure or function'. 'Nerve function' in this study refers to the sensory, motor and autonomic function of peripheral nerve trunks. In BANDS, nerve function is assessed by testing the functioning of innervated organs such as muscles and sensory mechanoreceptors, rather than the nerve fibres themselves. NFI is thus 
defined as 'clinically detectable impairment of motor, sensory or autonomic nerve function'. The level of impairment that is clinically detectable depends on the sensitivity of the instrument or method of testing used. It does not include impairment of nerve conduction that is only detectable by electrophysiological means. Finally, 'acute' (or recent) NFI is defined as NFI of up to and including 6 months duration. Autonomic function is not easily tested by clinical means alone, and therefore plays no practical role in the detection of NFI in this study.

Various underlying aetiological processes lead to nerve function NFI in leprosy patients. These are recognized as separate clinical entities, including reversal (or type 1) reaction and erythema nodosum leprosum (ENL or type 2 reaction). However, even in the absence of signs and symptoms of leprosy reactions, NFI can develop within a relatively short time span. This is usually referred to as "silent neuropathy, ${ }^{4}$ or "silent neuritis" ${ }^{11}$ or 'quiet nerve paralysis. ${ }^{12} \mathrm{~A}$ problem sometimes encountered in leprosy control is that the indication to treat NFI with corticosteroids is based on the clinical picture of leprosy reactions, and that this treatment is restricted to severe cases that are admitted to hospital. The intention of treatment is sometimes to reduce symptoms such as fever, pain, and oedema, and not necessarily to prevent permanent NFI. This is perhaps less the case nowadays, since the publication of several papers in the 1990s that highlighted the need for field-based corticosteroid treatment to be available for patients, not necessarily prescribed by a doctor, and more focused on NFI. ${ }^{6,13,14}$ However, the message that the focus of managing leprosy patients should be on the condition of their peripheral nerves remains one of central importance. Nerve function needs to be assessed regularly to detect (often insidious) changes accurately from month to month and respond with appropriate therapy. Both diagnosis and treatment of NFI need to be simple and feasible at field level.

From this operational perspective, NFI has been taken as the outcome indicator for the prospective cohort study introduced in this paper. The focus is thus primarily on the nerve.

\section{Study design}

BANDS is a prospective cohort study. It is based within the routine activities of a welldeveloped vertical leprosy control programme. New leprosy cases were enrolled continuously over a 12-month period. The patients were treated with multidrug therapy (MDT) as recommended by $\mathrm{WHO}$, and are being followed up for a period of 3 years in the case of paucibacillary (PB) patients and 5 years for multibacillary (MB) patients from the date of registration. During the follow-up period, patients are being assessed regularly for the presence of specific risk factors and monitored for any development of signs and symptoms of acute NFI during and after leprosy treatment. The treatment of acute NFI is according to fixed regimens in the field, with severe and complicated cases referred to hospital.

\section{Cohort size}

It was estimated that a total sample of 2000-3000 new leprosy patients would enable the detection of significant associations between acute NFI and the most important risk factors. 


\section{Risk factors under study}

- Leprosy grouping (paucibacillary, multibacillary)

- Leprosy classification (Ridley-Jopling)

- Skin smear result

- Skin lesion count

- Anti-leprosy treatment

- Age

- Sex

- Duration of symptoms before diagnosis

- Existence of nerve function impairment at time of diagnosis

- Nerve enlargement

- Leprosy reaction

- Mode of detection

- Distance to clinic

- Chronic disease status (e.g. diabetes, TB)

- Physical trauma/surgical operation

\section{Description of the control programme}

The study is based at the Danish Bangladesh Leprosy Mission (DBLM) in Nilphamari, northwest Bangladesh. The project, which started in 1977, is presently administered by The Leprosy Mission (TLM). The area has the highest prevalence of leprosy in the country ${ }^{9}$ with a case detection rate in 1996 of 5.7 per 10,000 population. DBLM is responsible to the Government of Bangladesh for administering a leprosy control programme covering the four northern districts of Nilphamari, Rangpur, Thakurgaon and Panchagar. The population according to the 1991 Census is $5,529,600$ and the area covered is 7163 square kilometres.

Bangladesh is a flat, riverine delta with a monsoon climate. The population is primarily rural $(>80 \%)$. Communications are good, with roads of reasonable standard reaching remote areas. This ease of communication makes it relatively uncomplicated for patients to attend clinics and for field staff to trace defaulters. The leprosy control activities in the four districts are administered by four Leprosy Control Officers (LCOs) who relate to a medically qualified Field Director. Leprosy Control Supervisors (LCSs) supervise activities at sub-district or 'thana' level, with Leprosy Control Assistants (LCAs) at grassroots level. Fifty to 60 clinics operate in the project area, at least monthly but often more frequently. There are over 100 field staff at different levels. Each clinic is attended by a LCS, LCAs, a Physio-technician and a Footwear Technician. Day to day management of leprosy patients is largely the responsibility of the LCS who confirms diagnosis, starts MDT, and in collaboration with the Physiotechnician, may start prednisolone in the field for patients with reactions or acute NFI.

\section{Recruitment and admission procedures}

SELECTION OF THE PATIENT

Inclusion criteria

- All newly diagnosed and previously untreated leprosy patients living in the leprosy control area, with or without acute nerve damage. 
- Newly diagnosed but previously treated leprosy patients living in the leprosy control area with a past history of incomplete DDS monotherapy or WHO-MDT.

\section{Exclusion criteria}

- Leprosy patients living outside the leprosy control area.

- Relapse cases.

INITIAL ASSESSMENT OF PATIENT

History

- Previous personal history and past treatment of leprosy.

- Duration of leprosy symptoms.

- Risk factors for acute NFI.

- Detailed clinical examination.

Skin

- Number and location of lesions.

- Type of lesion.

- Anaesthesia in lesions.

- Signs of inflammation in lesions (heat, erythema, swelling, pain).

- Oedema of hands/feet.

\section{Nerves}

- Systematic palpation of the following nerves: facial, radial, ulnar, median, lateral popliteal, posterior tibial. The degree (and score) of enlargement is recorded as follows: no enlargement (0); slightly enlarged (1); moderately enlarged (2) and very enlarged (3). Other cutaneous nerves (e.g. radial cutaneous, supraorbital, sural) are also palpated and the presence of enlargement recorded on the body chart. This is helpful in the diagnosis of leprosy, but in BANDS only the enlargement of the six main truncal nerves was recorded for analysis.

- Check for pain, tenderness and enlargement. The recording and scoring system is given in Table 1.

Table 1. Nerve pain recording and scoring system

\begin{tabular}{lc}
\hline Definition & Score \\
\hline No pain or tenderness & 0 \\
Slight pain complaint only/tender on pressure & 1 \\
Painful at work, sleep not disturbed & 2 \\
Pain disturbs sleep & 3 \\
\hline
\end{tabular}


Nerve function tests

Sensory testing $(S T)$

- Sensory testing of the palms of the hands and soles of the feet is routinely carried out at every clinic visit by LCAs. Any abnormality is referred to the Physio-technician and LCS. Testing is carried out using a ball-point pen, as described by Jean Watson ${ }^{15}$ at 12 standard points on each palm, and on 11 points on the soles. On the palm, five points are taken as supplied by the ulnar nerve and seven for the median (see Appendix 1).

Corneal sensory testing

- Each patient is observed whilst being examined to see whether blinking is normal. If so, no further testing is done. If blinking is less than 5 per minute, sensation is directly tested by applying a thin twist of clean cotton wool to the cornea whilst the patient looks up. Absence of involuntary blink response (in addition to the low blink rate already observed) is taken to be indicative of corneal anaesthesia.

Motor testing

- Motor testing is also carried out by trained Physio-technicians on every patient at every clinic visit, using a modified 5-point MRC scale (Table 2). ${ }^{16}$ Muscle movements that are routinely tested for by means of a 'quick muscle test' (QMT) are shown in Table 3. Patients with abnormalities undergo a more detailed assessment by a Physio-technician, but the decision to treat is usually based on the QMT.

\section{Wounds and deformities}

- Presence of ulcers on palms or soles; size; presence of infection.

- Presence of visible deformities e.g. claw hand, drop foot, etc.

\section{Skin smears}

Skin smears are normally taken from one ear lobe and the edges of two active lesions (or both sides of one lesion if only one is present). In cases where skin lesion edges cannot be clearly discerned (i.e. LL, PN cases) smears are taken from both ear lobes and the forehead. Reading takes place at one of the two laboratories, in Nilphamari or Thakurgaon.

Table 2. Modified 5-point MRC scale for muscle strength scoring

\begin{tabular}{|c|c|c|}
\hline Hands and feet & MRC grade & Eyes \\
\hline Full ROM $^{1}$, full resistance & 5 & Normal muscle strength \\
\hline Full $\mathrm{ROM}^{1}$, reduced resistance & 4 & Closes, stays closed against some resistance \\
\hline Full $\mathrm{ROM}^{1}$, no resistance & 3 & $\begin{array}{l}\text { Closes fully on strong closure, no resistance (may be } \\
\text { gap on gentle closure) }\end{array}$ \\
\hline Reduced ROM', some joint movement & 2 & Gap on strong closure ${ }^{2}$ \\
\hline Flicker only & 1 & Flicker only \\
\hline Full paralysis & 0 & Complete paralysis \\
\hline
\end{tabular}

\footnotetext{
${ }^{1}$ ROM: range of movement.

${ }^{2}$ In addition, lid gap in $\mathrm{mm}$ is measured and recorded.
} 
Table 3. Movements/muscles tested (quick muscle test, QMT)

\begin{tabular}{lll}
\hline Nerve & \multicolumn{1}{c}{ Movement } & Muscle/muscle group \\
\hline Ulnar & Little finger abduction & Abductor digiti minimi \\
Median & Thumb abduction & Abductor pollicis brevis \\
Radial & Wrist extension & Wrist extensors \\
Lateral popliteal & Foot dorsiflexion & Foot dorsiflexors \\
Facial & Closes eyes (strong and gentle closure tested) & Orbicularis oculi \\
& & \\
\hline
\end{tabular}

\section{Diagnosis of leprosy}

Leprosy was diagnosed when at least one of the following criteria was present:

- Hypopigmented or erythematous skin lesions with reduced or absent sensation.

- Enlarged nerves with or without NFI.

- Acid fast bacilli of characteristic appearance in skin smears.

\section{Classification of leprosy}

Patients were classified for treatment purposes as MB or PB according to the national guidelines used in Bangladesh. ${ }^{17}$ These guidelines classify as MB those cases where the total number of skin patches and palpably enlarged nerves ('nerve lesions') is 10 or more and/or the skin smear is positive; and they classify as PB those cases where the total number of skin patches and nerve lesions is less than 10 and which are smear negative. An analysis of the BANDS database has shown that this system of classification produces results very similar to the more conventional 'WHO system' which uses a skin lesion count only to classify into $\mathrm{PB}$ and $\mathrm{MB}\left(<6\right.$ skin patches $\mathrm{PB} ; \geq 6$ patches MB. ${ }^{18}$ In addition, leprosy cases are routinely classified clinically according to the scale described by Ridley and Jopling, ${ }^{19}$ adding the indeterminate (I) and pure neural (PN) groups included by some other classification systems such as the Indian. ${ }^{20}$

\section{Treatment}

All patients have been treated according to WHO guidelines for MDT current at the time of the study: PB cases: rifampicin $600 \mathrm{mg}$ supervised dose, DDS $100 \mathrm{mg}$ daily, total 6 months treatment; MB cases: rifampicin $600 \mathrm{mg}$ and clofazimine $300 \mathrm{mg}$ supervised dose, DDS $100 \mathrm{mg}$ daily and clofazimine $50 \mathrm{mg}$ daily, total 24 monthly doses. This dose regimen is used for all normal-sized adults; lower doses for small adults and children are given as described in the Bangladesh national treatment guidelines. ${ }^{17}$

FOLLOW-UP

The follow-up period starts at registration and continues for 3 years in PB cases and 5 years in $\mathrm{MB}$ cases. The frequency of assessment varies according to the patient's treatment status, 'released from treatment' (RFT) patients being followed up less frequently. Each assessment includes the following: (1) examination of skin and nerves; (2) nerve function tests 
(ST/QMT); (3) identification of specific risk factors; and (4) appropriate health education advice for regularity of MDT, complications of leprosy, side effects of treatment and self care for prevention of disability. All tests and assessments are carried out blind of previous tests and field staff actively follow up defaulting cases as a normal part of their work.

\section{ACUTE NERVE FUNCTION IMPAIRMENT/REACTION}

All patients are instructed to report to the clinic (in addition to routine follow-up visits) if they develop any signs and symptoms of reaction/NFI such as:

- Change in appearance of skin lesions

- New skin lesions

- Pain

- Weakness

- Paraesthesia/anaesthesia

They will be examined by an LCS and a Physio-technician who will diagnose any reactive phenomena and give treatment according to the DBLM treatment guidelines. ${ }^{21}$ This will usually be given in the field, but serious cases are referred to hospital for more intensive management.

\section{Follow-up of acute nerve function impairment}

Patients receiving prednisolone in the field according to the DBLM treatment guidelines are assessed weekly at home or in the clinic by field staff for the first month, and fortnightly thereafter. Assessment includes sensory and motor testing, and checking for drug compliance and side effects. Any complications are immediately referred to the supervisor, who may decide to admit the patient to hospital.

\section{Definitions of acute nerve function impairment and reactive treatment events}

At the time of the study start-up, the criteria used to define acute NFI and reactive events was that used in the DBLM treatment guidelines. ${ }^{21}$ In summary, this system defined a 'reactive event' (i.e. NFI/reaction requiring treatment using prednisolone in therapeutic doses) as follows: a patient in whom the sum of sensory, motor, nerve pain and skin scores was $\geq 2$, and where the duration of the score was 6 months or less. The scores could be generated from any nerves, and could be added between nerves and modalities (e.g. left ulnar sensory score + right facial motor score). However, as the study progressed, the study group decided that this system was over-sensitive. Further, it was felt that it was not logical to add scores between different nerves and modalities to arrive at a composite score. As a result, the group adopted the criteria given in Tables 4(a) and (b) to define NFI/reactive events requiring treatment. Importantly, NFI is defined as a reduction by $\geq 2$ in the motor or sensory score of any one nerve only, with no summation of scores between nerves or modalities. These definitions were developed from another major study, the Trials in Prevention of Disability currently running in Bangladesh and Nepal.

Since all nerve test scores are stored in the database, prevalences of NFI can be generated 
Table 4. (a) Definitions of NFI and reactions used in analysis

Term used

Nerve function impairment (NFI)

Partial nerve function impairment (partial NFI)

Severe nerve pain

Mild nerve pain

Type 1 reaction

Type 2 reaction
Definition

Sensory: Reduction by $\geq 2$ points in the sensory distribution of any one nerve

Motor: Reduction by $\geq 2$ in the MRC grade of the movement tested of any one nerve

Sensory: Reduction by 1 point in the sensory distribution of any one nerve Motor: Reduction by 1 in the MRC grade of the movement tested of any one nerve

Score of $\geq 2$ in the pain score of any one nerve

Score of 1 in the pain score of any one nerve

Inflammation of skin lesions characterized by swelling, erythema, local heat and tingling or pain. It may be accompanied by nerve function impairment

Reaction occurring in lepromatous cases only characterized by painful skin nodules (erythema nodosum leprosum, ENL), fever, and sometimes other organ involvement: lymphadenitis, orchitis, iridocyclitis. In addition, nerves may be involved with nerve pain/tenderness or nerve function impairment

(b) Criteria for defining a treatment event

- Sensory NFI in any one nerve

- Motor NFI in any one nerve

- Nerve pain (severe) in any one nerve

- Type 1 or 2 reaction

- Composite score of partial sensory or motor NFI + mild nerve pain in the same nerve

In this system, scores cannot be added between different nerves or different modalities except in the single case of partial NFI and mild pain in the same nerve.

using any criteria, and the revised definitions are used in all analysis. However, patient management was affected by this change. In subsequent papers describing the incidence of NFI and response to treatment, this will be examined more closely.

\section{Data collection and analysis}

Data relating to patients has been collected in a routine way using standard DBLM registration cards, treatment sheets and nerve function testing sheets. In addition, a special BANDS data form has been introduced to enable monthly follow-up data and questions relating to risk factors to be recorded.

A special relational database computer program was written using Microsoft FoxPro 2.6 for Windows. The process of data audit began early on during patient enrolment. Simple quality check programmes were developed using Epi Info software. Besides this, a full clinical audit was undertaken of the records of all patients considered to be at risk of developing a leprosy reaction (MB patients, any patient who had a reactional episode, and any patient with nerve function impairment at registration). 


\section{Description of the cohort at intake}

Recruitment for the BANDS cohort was started in April 1995 and completed after 12 months of intake. The number of patients in the BANDS cohort is 2664. Figure 1 shows the distribution of patients according to 5-year age bands, and sex. There are a total of 1481 males and 1183 females included (M:F ratio 1.25). Of all patients, $469(17 \cdot 61 \%)$ are children (age $<15$ years).

Table 5 summarizes the number of patients according to the PB/MB and Ridley-Jopling classifications, and according to bacteriological index (BI). $83.33 \%$ are classified as $\mathrm{PB}$, and $16.67 \%$ as MB leprosy. Of the MB cases, $36.71 \%$ are skin smear positive. Table 6 shows the breakdown by sex and leprosy group. The proportion of males with MB leprosy (19.71\%) is $53 \%$ higher than that amongst females $(12 \cdot 85 \%)$.

Figure 2 shows the duration of symptoms before diagnosis, registration and treatment with MDT among patients in the cohort. Just over half of all patients (55\%) reported having noticed symptoms up to 1 year before registration. The remaining patients reported having symptoms for more than a year, with $18 \%$ having symptoms for over 3 years.

Table 7 summarizes the number of patients with WHO disability grading 0,1 and 2, broken down by sex and leprosy group. A total of 2249 (84.42\%) had no disability at intake. $9.61 \%$ had disability grade 1 , and $5.97 \%$ had grade 2 . Both grade 1 and 2 disability prevalences in males are almost double those in females. Disability rates are 4-5 times higher amongst MB cases compared with PB.

Table 8 and Figure 3 show the number of nerves with sensory and motor NFI at registration. This includes nerves with both acute and longstanding NFI. The posterior tibial is the most frequently affected nerve with $6.46 \%$ affected ( $9.38 \%$ of patients), followed by the ulnar with $3.23 \%$ of nerves affected by either sensory or motor NFI $(5.56 \%$ of patients).

Table 9 shows the presence of acute NFI/reactive events at the time of registration. The definitions used are strictly those presented in Table 4. Ninety patients (3.38\%) had acute NFI at registration, of whom $61(67.78 \%)$ were patients with no other signs (i.e. silent neuritis).

Three hundred and sixteen patients had sensory NFI present at registration $(11.90 \%)$. Amongst MB patients 166 (37.39\%) were sensory impaired, but only 150 (6.76\%) of PB patients were sensory impaired. One hundred and ninety-seven patients had motor NFI present at registration (7.39\%). Amongst MB patients, 92 (20.72\%) were motor function impaired, and $105 \mathrm{~PB}$ patients had motor NFI present (4.73\%). A total of 381 patients had sensory and/or motor NFI present (14.30\%), 181 amongst MB patients (40.77\%) and 200 amongst PB patients $(9 \cdot 01 \%)$.

\section{Discussion}

Since it is nerve damage which is the cause of most deformity and consequent disability, handicap and stigmatization, NFI is the principal outcome measure of the study. The objective of the study is to describe accurately the associations of NFI with the risk factors under observation so that patients at risk of developing NFI can be identified. The study is field-based and all the techniques used for measuring NFI were already being used in the control programme, and in the routine work carried out for all leprosy patients at every 


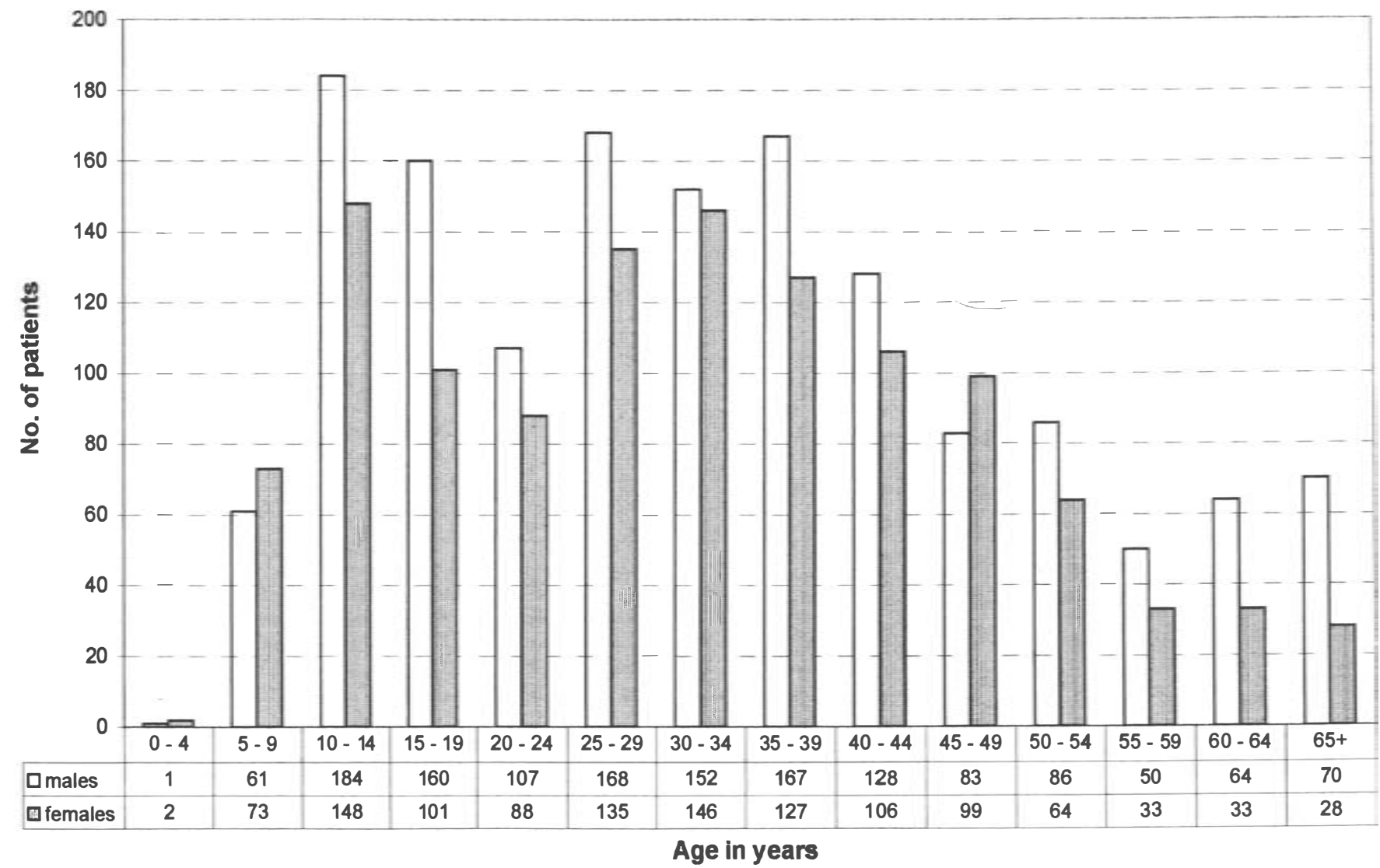

7
0
0
0
0
0
0

Figure 1. BANDS intake cohort-age/sex distribution. 
Table 5. Leprosy group, Ridley-Jopling classification and bacteriological index of BANDS cohort

\begin{tabular}{|c|c|c|c|c|c|c|c|c|c|c|}
\hline \multicolumn{5}{|c|}{ Classification } & \multicolumn{6}{|c|}{ Bacteriological Index } \\
\hline \multirow{2}{*}{$\begin{array}{l}\text { Ridley-Jopling } \\
\text { I }\end{array}$} & \multirow{2}{*}{$\begin{array}{r}\text { PB } \\
49\end{array}$} & \multirow{2}{*}{$\begin{array}{r}\text { MB } \\
0\end{array}$} & \multicolumn{2}{|c|}{ Total } & \multirow{2}{*}{$\begin{array}{c}\text { Unknown } \\
1\end{array}$} & \multirow{2}{*}{$\begin{array}{l}0 \\
48\end{array}$} & \multirow{2}{*}{$\frac{\leq 3+}{0}$} & \multirow{2}{*}{$\frac{\geq 4+}{0}$} & \multicolumn{2}{|c|}{ Total BI + ve } \\
\hline & & & 49 & $1 \cdot 84 \%$ & & & & & 0 & $0.00 \%$ \\
\hline TT & 263 & 0 & 263 & $9 \cdot 87 \%$ & 4 & 259 & 0 & 0 & 0 & $0.00 \%$ \\
\hline BT & 1801 & 286 & 2087 & $78 \cdot 34 \%$ & 21 & 2040 & 26 & 0 & 26 & $1.25 \%$ \\
\hline BB & 1 & 17 & 18 & $0.68 \%$ & 1 & 13 & 3 & 1 & 4 & $22.22 \%$ \\
\hline $\mathrm{BL}$ & 0 & 84 & 84 & $3 \cdot 15 \%$ & 0 & 0 & 30 & 54 & 84 & $100 \cdot 00 \%$ \\
\hline LL & 0 & 51 & 51 & $1.91 \%$ & 0 & 2 & 6 & 43 & 49 & $96.07 \%$ \\
\hline PN & 106 & 6 & 112 & $4 \cdot 10 \%$ & 1 & 111 & 0 & 0 & 0 & $0.00 \%$ \\
\hline Total & $\begin{array}{c}2220 \\
83.33 \%\end{array}$ & 444 & 2664 & & 28 & 2473 & 65 & 98 & 163 & \\
\hline & $83 \cdot 33 \%$ & $16.67 \%$ & $100 \cdot 00 \%$ & $100 \cdot 0 \%$ & $1 \cdot 05 \%$ & $92 \cdot 83 \%$ & $2.45 \%$ & $3.68 \%$ & $6 \cdot 12 \%$ & \\
\hline
\end{tabular}

clinic attendance. Thus, it is hoped that the results will be applicable to leprosy control programmes.

DBLM has been using the ballpoint pen test $(\mathrm{BPT})^{15}$ for sensory function testing for many years before starting the study, and this method of testing was continued for BANDS. The BPT is advocated on the grounds that is cheap and readily available, and criticized on the grounds that the force applied may vary considerably and therefore the results are likely to be unreliable. ${ }^{22}$ Also, since it is a threshold (yes/no only) test it relies on a count of the number of sites at which gross sensation is lost to provide an indication of the level of sensory loss. On the other hand, graded monofilament testing (as described by Bell-Krotoski ${ }^{23}$ ) is advocated on the grounds that the results are reliable, since the force required to bend the accurately manufactured monofilaments is relatively constant and repeatable, ${ }^{24}$ and since they are a graded test they provide a quasi-quantitative estimate of sensory loss. The monofilament test is sometimes criticized on the grounds that the monofilaments used are less easily available, and too 'technical' and time-consuming for widespread use. Lienhardt, Currie and Wheeler carried out inter-observer testing using BPT, monofilament and voluntary muscle testing (VMT) in Ethiopia. ${ }^{25}$ They found a $32-58 \%$ agreement using monofilaments with a weighted kappa $\left(\kappa_{\mathrm{w}}\right)$ statistic of $0 \cdot 736-0.814$, indicating good agreement $\left(\kappa_{\mathrm{w}} \geq 0.60\right.$ indicates good agreement) and an agreement of $71-84 \%, \kappa_{\mathrm{w}} 0.604-0.793$ with the BPT. In an inter-observer reliability test recently carried out at DBLM, the $\kappa_{\mathrm{w}}$ for BPT was $0 \cdot 86$, and for monofilaments was $0 \cdot 92 .{ }^{26}$ Both these studies confirm that BPT can be adequate for study purposes. However, since the test is less sensitive than monofilament testing, the prevalence of SNFI detected by BPT will be an comparative underestimate. A cohort of sufficient size

Table 6. Sex and leprosy group

\begin{tabular}{llrrrrr}
\hline Sex & \multicolumn{2}{c}{ PB } & \multicolumn{2}{c}{ MB } & \multicolumn{2}{c}{ Total } \\
\hline Male & 1189 & $80 \cdot 28 \%$ & 292 & $19 \cdot 72 \%$ & 1481 & $55 \cdot 59 \%$ \\
Female & 1031 & $87 \cdot 15 \%$ & 152 & $12 \cdot 85 \%$ & 1183 & $44 \cdot 41 \%$ \\
Total & 2220 & $83 \cdot 33 \%$ & 444 & $16 \cdot 67 \%$ & 2664 & $100 \cdot 00 \%$ \\
\hline
\end{tabular}




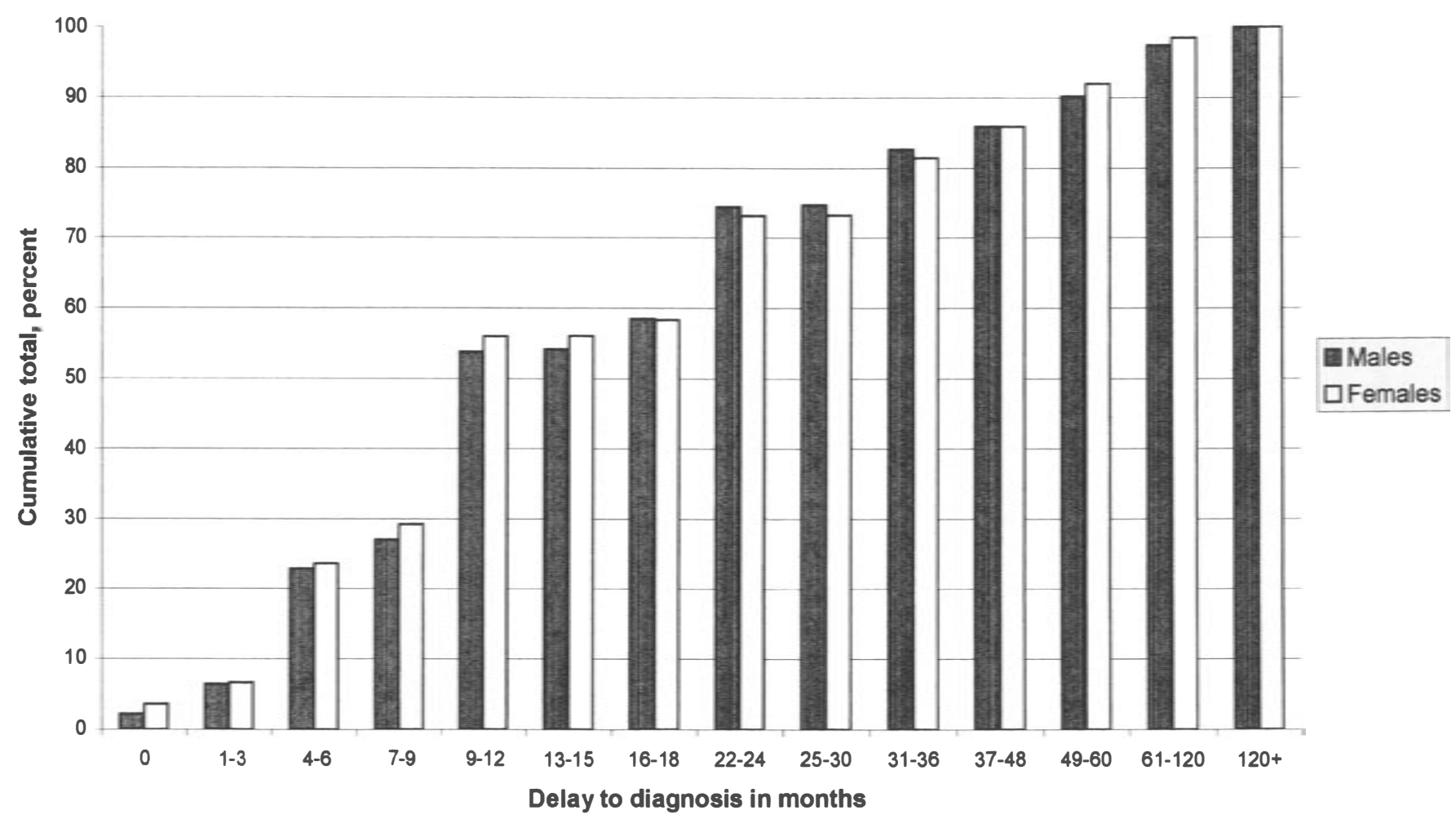

Figure 2. Bar graph showing delay to diagnosis by sex amongst patients in the BANDS cohort. 
Table 7. WHO disability grades by sex and leprosy group

\begin{tabular}{|c|c|c|c|c|c|c|c|c|c|c|}
\hline \multirow{2}{*}{$\begin{array}{l}\text { Disability grade } \\
0\end{array}$} & \multicolumn{2}{|c|}{ Males } & \multicolumn{2}{|c|}{ Females } & \multicolumn{2}{|r|}{ MB } & \multicolumn{2}{|r|}{ PB } & \multicolumn{2}{|c|}{ Total } \\
\hline & 1196 & $80.76 \%$ & 1053 & $89.01 \%$ & 241 & $54.28 \%$ & 2008 & $90 \cdot 45 \%$ & 2249 & $84.42 \%$ \\
\hline 1 & 174 & $11.75 \%$ & 82 & $6.93 \%$ & 122 & $27.48 \%$ & 134 & $6 \cdot 04 \%$ & 256 & $9.61 \%$ \\
\hline 2 & 111 & $7.49 \%$ & 48 & $4.06 \%$ & 81 & $18 \cdot 24 \%$ & 78 & $3.51 \%$ & 159 & $5.97 \%$ \\
\hline Total & 1481 & $100 \cdot 00 \%$ & 1183 & $100 \cdot 0 \%$ & 444 & $100 \cdot 00 \%$ & 2220 & $100 \cdot 00 \%$ & 2664 & $100 \cdot 00 \%$ \\
\hline
\end{tabular}

(2664) was recruited to achieve the aims of the study. The male:female ratio is $1 \cdot 25$, while the true sex ratio in the community is $1 \cdot 05: 1$. The relatively high child rate $(17.61 \%)$ is similar to rates obtained in other parts of Bangladesh, and reflects in part a continuing high level of transmission of $M$. leprae, and in part the operational emphasis on school health education programmes and surveys carried out by the field staff.

Table 8. Nerve function impairment at intake by nerve (5328 of each nerve)

\begin{tabular}{|c|c|c|c|c|c|c|c|}
\hline \multirow[b]{2}{*}{ Nerve } & \multirow[b]{2}{*}{ Side } & \multicolumn{2}{|c|}{ Sensory NFI } & \multicolumn{2}{|c|}{ Motor NFI } & \multicolumn{2}{|c|}{ Sensory or motor NFI } \\
\hline & & $\begin{array}{l}\text { Nerves } \\
\text { involved }\end{array}$ & $\begin{array}{l}\% \text { nerves } \\
\text { involved }\end{array}$ & $\begin{array}{l}\text { Nerves } \\
\text { involved }\end{array}$ & $\begin{array}{l}\% \text { nerves } \\
\text { involved }\end{array}$ & $\begin{array}{l}\text { Nerves } \\
\text { involved }\end{array}$ & $\begin{array}{l}\% \text { nerves } \\
\text { involved }\end{array}$ \\
\hline \multirow{4}{*}{ Facial } & $\mathrm{R}$ & & & 22 & $0 \cdot 83$ & 22 & $0 \cdot 83$ \\
\hline & $\mathrm{L}$ & & & 20 & 0.75 & 20 & 0.75 \\
\hline & $\mathrm{R}+\mathrm{L}$ & & & 42 & 0.79 & 42 & 0.79 \\
\hline & $\mathrm{R}$ or $\mathrm{L}$ & & & 32 & $1 \cdot 20$ & 32 & $1 \cdot 20$ \\
\hline \multirow{4}{*}{ Ulnar } & $\mathrm{R}$ & 65 & $2 \cdot 44$ & 77 & $2 \cdot 89$ & 92 & 3.45 \\
\hline & $\mathrm{L}$ & 59 & $2 \cdot 21$ & 61 & $2 \cdot 29$ & 80 & 3.00 \\
\hline & $\mathrm{R}+\mathrm{L}$ & 124 & $2 \cdot 33$ & 138 & 2.59 & 172 & $3 \cdot 23$ \\
\hline & $\mathrm{R}$ or $\mathrm{L}$ & 106 & 3.98 & 123 & 4.62 & 148 & $5 \cdot 56$ \\
\hline \multirow{4}{*}{ Median } & $\mathrm{R}$ & 51 & 1.91 & 21 & 0.79 & 56 & $2 \cdot 10$ \\
\hline & $\mathrm{L}$ & 54 & 2.03 & 22 & 0.83 & 61 & 2.29 \\
\hline & $\mathrm{R}+\mathrm{L}$ & 105 & 1.97 & 43 & $0 \cdot 81$ & 117 & $2 \cdot 20$ \\
\hline & $\mathrm{R}$ or $\mathrm{L}$ & 86 & $3 \cdot 23$ & 38 & 1.43 & 97 & 3.64 \\
\hline \multirow{4}{*}{ Radial } & $\mathrm{R}$ & & & 2 & 0.08 & 2 & 0.08 \\
\hline & $\mathrm{L}$ & & & 3 & 0.11 & 3 & $0 \cdot 11$ \\
\hline & $\mathrm{R}+\mathrm{L}$ & & & 5 & 0.09 & 5 & 0.09 \\
\hline & $\mathrm{R}$ or $\mathrm{L}$ & & & 4 & $0 \cdot 15$ & 4 & $0 \cdot 15$ \\
\hline \multirow{4}{*}{$\begin{array}{l}\text { Lateral } \\
\text { popliteal }\end{array}$} & $\mathrm{R}$ & & & 27 & 1.01 & 27 & $1 \cdot 01$ \\
\hline & $\mathrm{L}$ & & & 36 & 1.35 & 36 & 1.35 \\
\hline & $\mathrm{R}+\mathrm{L}$ & & & 63 & $1 \cdot 18$ & 63 & $1 \cdot 18$ \\
\hline & $\mathrm{R}$ or $\mathrm{L}$ & & & 58 & $2 \cdot 18$ & 58 & $2 \cdot 18$ \\
\hline \multirow{4}{*}{$\begin{array}{l}\text { Posterior } \\
\text { tibial }\end{array}$} & $\mathrm{R}$ & 168 & $6 \cdot 31$ & & & 168 & $6 \cdot 31$ \\
\hline & $\mathrm{L}$ & 176 & 6.61 & & & 176 & $6 \cdot 61$ \\
\hline & $\mathrm{R}+\mathrm{L}$ & 344 & 6.46 & & & 344 & $6 \cdot 46$ \\
\hline & $\mathrm{R}$ or $\mathrm{L}$ & 250 & $9 \cdot 38$ & & & 250 & $9 \cdot 38$ \\
\hline \multirow{4}{*}{ Any } & $\mathrm{R}$ & 213 & $8 \cdot 00$ & 120 & $4 \cdot 50$ & 255 & 9.57 \\
\hline & $\mathrm{L}$ & 214 & 8.03 & 108 & $4 \cdot 05$ & 255 & 9.57 \\
\hline & $\mathrm{R}+\mathrm{L}$ & 427 & $8 \cdot 01$ & 228 & $4 \cdot 28$ & 510 & 9.57 \\
\hline & $\mathrm{R}$ or $\mathrm{L}$ & 316 & 11.90 & 197 & $7 \cdot 39$ & 381 & $14 \cdot 30$ \\
\hline
\end{tabular}




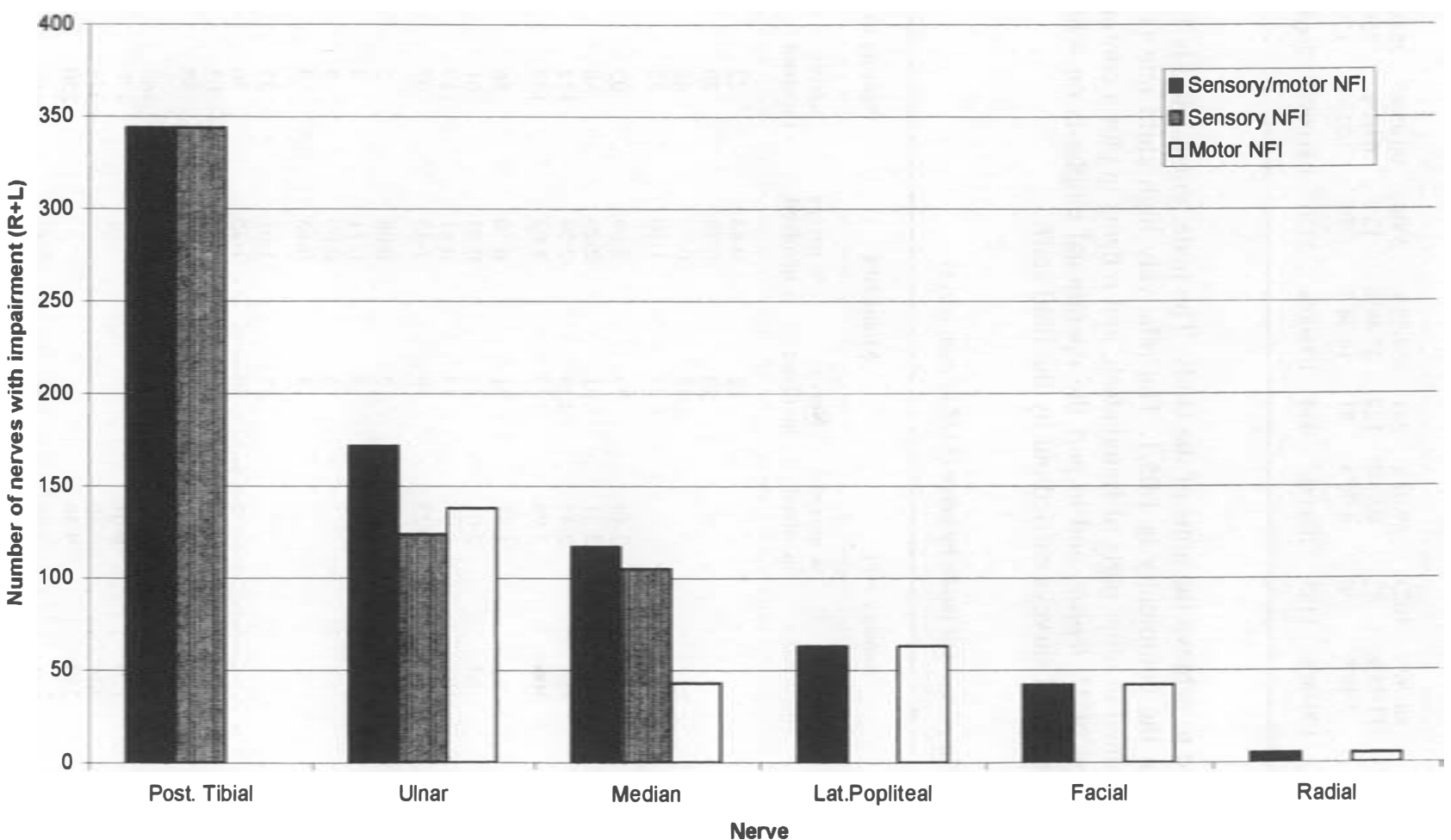

Figure 3. Graph showing number of nerves with impairment of function amongst cohort, by nerve. 
Table 9. Acute reactive/NFI events at intake amongst BANDS cohort patients

\begin{tabular}{|c|c|c|c|c|c|c|c|}
\hline $\begin{array}{l}\text { Non-specific } \\
\text { terminology } \\
\text { of NFI/reaction }\end{array}$ & Specific terminology of NFI/reactions & Male & Female & MB & $\mathrm{PB}$ & $\begin{array}{c}\text { Total } \\
\text { (specific terminology) }\end{array}$ & $\begin{array}{c}\text { Total } \\
\text { (non-specific terminology) }\end{array}$ \\
\hline Neuritis & $\begin{array}{l}\text { NFI only (silent neuritis) } \\
\text { NFI + nerve pain } \\
\text { Nerve pain only } \\
\text { Partial NFI + mild nerve pain }\end{array}$ & $\begin{array}{r}45 \\
0 \\
0 \\
0\end{array}$ & $\begin{array}{r}16 \\
1 \\
0 \\
2\end{array}$ & $\begin{array}{r}25 \\
1 \\
0 \\
1\end{array}$ & $\begin{array}{r}36 \\
0 \\
0 \\
1\end{array}$ & $\begin{array}{r}61 \\
1 \\
0 \\
2\end{array}$ & 64 \\
\hline Type 1 reaction & $\begin{array}{l}\text { Type } 1+\text { NFI } \\
\text { Type } 1+\text { NFI + nerve pain } \\
\text { Type } 1+\text { nerve pain } \\
\text { Type } 1+\text { partial NFI + mild nerve pain } \\
\text { Type } 1 \text { only }\end{array}$ & $\begin{array}{r}15 \\
4 \\
2 \\
0 \\
15\end{array}$ & $\begin{array}{l}7 \\
1 \\
0 \\
0 \\
8\end{array}$ & $\begin{array}{r}16 \\
3 \\
1 \\
0 \\
18\end{array}$ & $\begin{array}{l}6 \\
2 \\
1 \\
1 \\
4\end{array}$ & $\begin{array}{r}22 \\
5 \\
2 \\
0 \\
23\end{array}$ & 52 \\
\hline Type 2 reaction & $\begin{array}{l}\text { Type } 2+\text { NFI } \\
\text { Type } 2+\text { nerve pain } \\
\text { Type } 2 \text { only }\end{array}$ & $\begin{array}{l}1 \\
0 \\
2\end{array}$ & $\begin{array}{l}0 \\
0 \\
0\end{array}$ & $\begin{array}{l}1 \\
0 \\
2\end{array}$ & $\begin{array}{l}0 \\
0 \\
0\end{array}$ & $\begin{array}{l}1 \\
0 \\
2\end{array}$ & 3 \\
\hline $\begin{array}{l}\text { Total cases with } \\
\text { any reaction or NFI }\end{array}$ & & 84 & 35 & 68 & 51 & 119 & 119 \\
\hline Total & & 1481 & 1183 & 444 & 2220 & 2664 & \\
\hline $\begin{array}{l}\text { Any reaction/NFI } \\
\text { prevalence }\end{array}$ & & $5 \cdot 67 \%$ & $2 \cdot 96 \%$ & $15 \cdot 32 \%$ & $2 \cdot 30 \%$ & $4 \cdot 20 \%$ & \\
\hline $\begin{array}{l}95 \% \text { confidence } \\
\text { intervals }\end{array}$ & & $(4 \cdot 57-7 \cdot 01)$ & $(2 \cdot 10-4 \cdot 14)$ & $(12 \cdot 16-19 \cdot 08)$ & $(1.73-3.03)$ & $(3 \cdot 73-5 \cdot 34)$ & \\
\hline Total cases with NFI & & 65 & 25 & 46 & 44 & 90 & \\
\hline NFI prevalence & & $4 \cdot 39 \%$ & $2 \cdot 11 \%$ & $10 \cdot 36 \%$ & $1.98 \%$ & $3 \cdot 38 \%$ & \\
\hline $\begin{array}{l}95 \% \text { confidence } \\
\text { intervals }\end{array}$ & & $(3 \cdot 43-5 \cdot 52)$ & $(1 \cdot 40-3 \cdot 15)$ & $(7 \cdot 76-13 \cdot 67)$ & $(1 \cdot 46-2 \cdot 68)$ & $(2 \cdot 74-4 \cdot 16)$ & \\
\hline
\end{tabular}


The high proportion of PB cases $(83.33 \%)$ probably reflects the success of the programme at early case finding, a notion supported by the finding that the majority of cases (73.8\%) report duration of symptoms as no longer than 24 months at the time of diagnosis. It is interesting that the MB proportion amongst males $(19.71 \%)$ is $53 \%$ higher than that amongst females $(12.85 \%)$. This does not represent a greater delay to diagnosis amongst men, since Figure 2 shows that the delay to diagnosis amongst males is almost the same as that amongst females; maybe the disease develops more rapidly in males.

The classification by Ridley-Jopling shows another weakly bimodal distribution with very high numbers of BT/TT patients, and another much smaller peak of BL patients. A similar kind of distribution was also found in other cohorts in Nepal and India. ${ }^{2,4,27,28}$ The proportion of pure neural leprosy (4.20\%) is significant, although it is much less than the $18 \%$ described by Noordeen from India. ${ }^{29}$ Overall, the smear positive rate amongst the cohort is low (6.12\%), but it is still a considerable rate amongst MB cases (36.71\%). Out of all the 163 smear positive cases, the majority $(98 / 163,60 \cdot 12 \%)$ had a high $\mathrm{BI}$ of $>3+$.

The WHO grade 2 disability (visible deformity, lagophthalmos with diminished visual acuity) prevalence among new cases is low at $5.97 \%$, indicating again that the programme is successful at early detection of cases. There is a greater number with grade 1 disability (anaesthesia, lagophthalmos with normal vision) who are at potential risk of secondary damage. (It should be noted that the most recent definition of grade 2 disability in eyes includes all lagophthalmos under grade $1^{30}$ ). MB cases show a markedly higher disability rate, $45.72 \%$ having either grade 1 or 2 compared to $9.55 \%$ amongst PB cases. Males show a WHO disability rate almost double that of females (grade 1, females - 6.93\%; males $11.75 \%$; grade 2 , females $-4.06 \%$; males $-7.49 \%$ ). This is in line with the higher proportion of MB cases amongst men and the higher prevalence of nerve damage amongst MB cases.

A total of $11.90 \%$ of the patients had sensory NFI of any kind, and $7.39 \%$ had motor NFI of any kind. This was rather less than van Brakel's findings with a cohort of new patients registering at a hospital in Nepal (29\% sensory impaired, 24\% motor impaired). ${ }^{4}$ Analysis by nerves affected shows an interesting ranking order, with the posterior tibial clearly the most commonly affected (6.46\% of nerves), followed by the ulnar with $3.23 \%$ of all nerves affected. Other nerves followed in this order: median $(2 \cdot 20 \%)$, lateral popliteal $(1 \cdot 18 \%)$, facial $(0.79 \%)$ and radial $(0.09 \%)$. This was very similar to the ranking found by Richardus and others in a retrospective cohort study carried out at DBLM, ${ }^{6}$ although palmar sensory loss was not divided into ulnar and median nerve distributions, and numbers presented were of patients affected, and not nerves.

The proportion of patients presenting in reaction or neuritis requiring treatment with prednisolone was $4.20 \%$ of the intake. The proportion of MB patients with a reaction or NFI $(15 \cdot 32 \%)$ is nearly 7 times higher than that for PB $(2 \cdot 30 \%)$, which is in line with others' findings that $\mathrm{MB}$ patients are at higher risk of developing reactions and neuritis. ${ }^{2}$ These findings agree with other studies conducted amongst field patients including a study by Boerrigter, ${ }^{31}$ who found a reversal reaction (RR) rate of $2.2 \%$ among TT and BT patients at registration; and Becx-Bleumink who found the rate of RR to be 3.4\% amongst BT patients and $4.9 \%$ amongst BLs. ${ }^{8}$ These rates are much lower than van Brakel's cohort of new hospital outpatients, with $30 \%$ of BT patients and $31 \%$ of BL patients presenting in RR. ${ }^{2}$ This may reflect later case presentation in Nepal, as others have noted; ${ }^{32}$ in addition, there was a higher proportion of MB patients amongst the Nepali group. Van Brakel's study was based at a referral centre, and the self-referred patients presenting are often those with a higher proportion of complications. Males appear to be at nearly double the risk of having a 
reaction or NFI needing treatment at diagnosis (5.67\%; females $2.96 \%$ ), a fact partly explained by the higher MB rate amongst men.

Of the 90 patients who presented with NFI needing treatment at diagnosis, $61(67.78 \%)$ were silent, that is, there were no other signs including nerve pain or skin reactions to call attention to the neuropathy. They represented $2.29 \%$ of the total intake. Van Brakel found that almost $7 \%$ of his retrospective cohort of 536 patients had silent neuritis at first examination. ${ }^{4}$ Bernink and Voskens found 28 out of 856 patients (3.3\%) in Indonesia who had silent neuritis. ${ }^{33}$ Both papers underline the need for routine sensory and motor testing of leprosy cases in order to identify such patients, and the BANDS study emphasizes this need if the prevention of disability is to be taken seriously.

\section{Future research}

This paper describes the design and methodology of the Bangladesh Acute Nerve Damage Study and the intake status of the cohort of 2664 patients. Future research and publications, building on this foundation, will focus on the following areas: the incidence of NFI and reactive events, the risk factors for developing NFI, and the response to treatment of patients developing acute NFI.

\section{Acknowledgements}

The authors are grateful for the enthusiasm and commitment of the staff at DBLM in carrying out this study in the field. Mr Pjotr Prins gave invaluable help in writing the computer database programme used for BANDS. Dr Alison M. Anderson gave generously of her time and expertise to help in advice and audit. Ms Hanna Møller wrote the manual for the computer programme. Dr Rosemary Croft made many helpful suggestions. I am indebted to Mrs Jane Denny for conscientiously editing the manuscript. BANDS is financially supported by The Leprosy Mission International.

\section{References}

${ }^{1}$ Lienhardt C, Fine PE. Type 1 reaction, neuritis and disability in leprosy. What is the current epidemiological situation? [see comments]. Lepr Rev, 1994; 65: 9-33.

2 Van Brakel WH, Khawas IB, Lucas SB. Reactions in leprosy: an epidemiological study of 386 patients in west Nepal. Lepr Rev, 1994; 65: 190-203.

3 Van Brakel WH, Khawas IB. Nerve damage in leprosy: an epidemiological and clinical study of 396 patients in west Nepal - part 1: definitions, methods and frequencies. Lepr Rev, 1994; 65: 204-221.

${ }^{4}$ Van Brakel WH, Khawas IB. Silent neuropathy in leprosy: an epidemiological description [see comments]. Lepr Rev, 1994; 65: 350-360.

5 Van Brakel WH, Khawas IB. Nerve function impairment in leprosy: an epidemiological and clinical study - part 2: results of steroid treatment. Lepr Rev, 1996; 67: 104-118.

${ }^{6}$ Richardus JH, Finlay KM, Croft RP, Smith WC. Nerve function impairment in leprosy at diagnosis and at completion of MDT: a retrospective cohort study of 786 patients in Bangladesh. Lepr Rev, 1996; 67: 297-305.

7 de Rijk AJ, Gabre S, Byass P, Berhanu T. Field evaluation of WHO-MDT of fixed duration, at ALERT, Ethiopia: the AMFES project - II. Reaction and neuritis during and after MDT in PB and MB leprosy patients. Lepr Rev, 1994; 65: 320-332.

8 Becx-Bleumink M, Berhe D. Occurrence of reactions, their diagnosis and management in leprosy patients treated with multidrug therapy; experience in the leprosy control program of the All Africa Leprosy and Rehabilitation Training Center (ALERT) in Ethiopia. Int J Lepr, 1992; 60: 173-84. 
9 Richardus JH, Croft RP. Estimating the size of the leprosy problem: the Bangladesh experience. Lepr Rev, 1995; 66: $158-164$.

10 Anonymous. International classification of impairments, disabilities and handicaps. Geneva: WHO, 1980.

11 Duncan ME, Pearson JM. Neuritis in pregnancy and lactation. Int J Lepr, 1982; 50: 31-38.

12 Srinivasan H, Rao KS, Shanmugam N. Steroid therapy in recent 'quiet nerve paralysis' in leprosy. Report of a study of twenty-five patients. Lepr India, 1982; 54: 412-419.

13 Becx-Bleumink M, Berhe D, Mannet je W. The management of nerve damage in the leprosy control services. Lepr Rev, 1990; 61: 1-11.

14 Rose P, Waters MF. Reversal reactions in leprosy and their management [editorial] [see comments]. Lepr Rev, 1991; 62: 113-121.

15 Watson JM. Essential action to minimise disability in leprosy patients. London: The Leprosy Mission, 1986.

16 Anonymous. Aids to the investigation of peripheral nerve injuries (Memo no. 7, 2nd edition). London: HMSO, 1962.

17 Anonymous. Technical guide and operational manual for leprosy control in Bangladesh. TB and leprosy control services, Government of Bangladesh, Dhaka, 1995.

18 Croft RP, Nicholls PG, Richardus JH, Smith WCS. Sensitivity and specificity of methods of classification of leprosy without the use of skin smear examination. Int J Lepr, 1998; in press.

19 Ridley DS, Jopling WH. Classification of leprosy according to immunity. A five-group system. Int J Lepr, 1966; 34: 255-273.

20 Dharmendra. Classifications. In: Hastings RC, ed. Leprosy. London: Churchill Livingstone, 1994.

${ }^{21}$ Croft RP, Richardus JH, Smith WC. Field treatment of acute nerve function impairment in leprosy using a standardized corticosteroid regimen - first year's experience with 100 patients. Lepr Rev, 1997; 68: 316-325.

22 Owen BM, Stratford CJ. Assessment of the methods available for testing sensation in leprosy patients in a rural setting. Lepr Rev, 1995; 66: 55-62.

${ }^{23}$ Bell-Krotoski JA. 'Pocket' monofilaments and specifications for the Semmes-Weinstein monofilaments. $J$ Hand Ther, 1990; 3: 26-31.

${ }^{24}$ Bell-Krotoski JA, Tomancik E. The repeatability of testing with Semmes-Weinstein monofilaments. $J$ Hand Surg, 1987; 12A: 155-161.

25 Lienhardt C, Currie H, Wheeler JG. Inter-observer variability in the assessment of nerve function in leprosy patients in Ethiopia. Int J Lepr, 1995; 63: 62-76.

26 Anderson AMA, Croft RP. Reliability of Semmes-Weinstein monofilament, ballpoint sensory testing and voluntary muscle testing in Bangladesh. Lepr Rev, submitted.

27 Lockwood, DN, Vinayakumar S, Stanley JN, McAdam KP, Colston MJ. Clinical features and outcome of reversal (type 1) reactions in Hyderabad, India. Int J Lepr, 1993; 61: 8-15.

28 Van Brakel WH, de Soldenhoff R, McDougall AC. The allocation of leprosy patients into paucibacillary and multibacillary groups for multidrug therapy, taking into account the number of body areas affected by skin, or skin and nerve lesions. Lepr Rev, 1992; 63: 231-246.

29 Noordeen SK. Epidemiology of (poly)neuritic leprosy. Lepr India, 1972; 44: 90-96.

30 Anonymous. WHO Expert Committee on Leprosy, 7th report. World Health Organization Technical Report Series, 1998; 874: 1-43.

31 Boerrigter G, Ponninghaus JM, Fine PE. Preliminary appraisal of a WHO-recommended multiple drug regimen in paucibacillary leprosy patients in Malawi. Int J Lepr, 1988; 56: 408-17.

32 Groenen G, Saha NG, Rashid MA, Hamid MA, S.R. P. Classification of leprosy cases under field conditions in Bangladesh. Lepr Rev, 1995; 66: 134-143.

33 Bernink EH, Voskens JE. Study on the detection of leprosy reactions and the effect of prednisolone on various nerves, Indonesia. Lepr Rev, 1997; 68: 225-232. 


\section{Appendix 1}

Diagram showing sensory function testing points used on soles and palms

\section{a Palms}

Points $1,2,3,6,7,8$ and 11 are taken as median nerve distribution Points 4, 5, 9, 10 and 12 are taken as ulnar nerve distribution

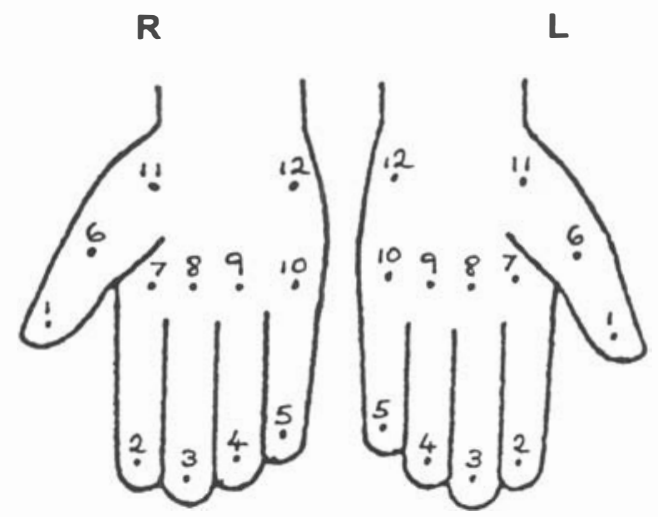

\section{b Soles}

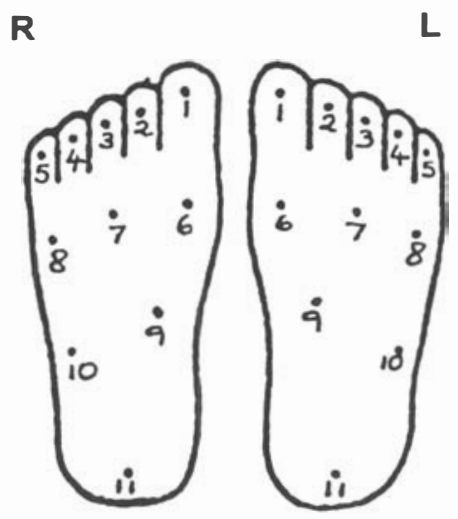

